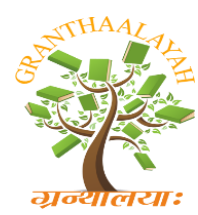

\author{
GRANTHAALAYAH \\ A knowledge Repository
}

INTERNATIONAL JOURNAL OF RESEARCH -

Science

\title{
EVALUATING THE SPECIFIC LEARNING MECHANISMS AND A LONGITUDINAL TRANSFORMATION OUTPUT BY USING THE PERFORMANCE INDICATORS
}

\author{
Daniel Sinkonde Kayange *1 \\ ${ }^{* 1}$ Department of Electronics and Telecommunication, Mbeya University of Science and \\ Technology, Mbeya, TANZANIA
}

\begin{abstract}
Due to rapid technological changes in the world today in many fields, there are ever widening technical skill gaps in the labour market of scientists, technicians and engineers. This paper builds on a seven-year study of transformation efforts of the technical education development of the Mbeya University of Science and Technology (MUST). The paper builds on the critical theoretical contribution and the live application transformation of the Mbeya University of Science and Technology (MUST). The report builds on exploring the mechanisms of designing and managing learning mechanisms as both transformations of the university into new entities development and retaining the ability to learn and transform all the time, even after becoming specialized.
\end{abstract}

Keywords:

clinical inquiry, field notes, Intervention research, Tanzania, University transformation.

Cite This Article: Daniel Sinkonde Kayange, "EVALUATING THE SPECIFIC LEARNING MECHANISMS AND A LONGITUDINAL TRANSFORMATION OUTPUT BY USING THE PERFORMANCE INDICATORS" International Journal of Research - Granthaalayah, Vol. 3, No. 12(2015): 150-162. DOI: https://doi.org/10.29121/granthaalayah.v3.i12.2015.2900.

\section{INTRODUCTION}

In the grown-up markets worldwide, learning mechanisms is a foundation stone of a firm's competitive advantage (Chapman et al., 2010; Docherty et al., 2008; Garvin, Edmondson, \& Gino, 2008). Developing the flexibility for fast allocation or reallocation of resources and the capability to customize products or services without compromising technological excellence and quality are critical (Verganti, 1999). Mature organizations find it challenging to design structures, processes, learning mechanisms, and systems that support ongoing needed transformation (Beer, Eisenstat, \& Foote, 2009; Phills, Deiglmeier, \& Miller, 2008). The appropriateness of traditional views on organization design, organizational change, and the management of change and development are being questioned within the context of the recent global economic downturn (Verganti, 2013). Organizations that counted on traditional ways of 
organizing and on previous successful change processes are finding out that they are not able to respond to the increasing demands for change (Worley \& Lawler, 2010).

The purpose of this paper is to explore the role and impact of the design, transformation, and management of learning mechanisms in enhancing ongoing university transformation in two major periods. Mbeya University of Science and Technology (MUST) is a product of the Mbeya Institute of Science and Technology (MIST) that was in operation since 2005 to 2012. Mbeya Institute of Science and Technology (MIST) is a product of the Mbeya Technical College that was in operation since 1986 to 2005. The Government of the United Republic of Tanzania established Mbeya Technical College (MTC) during the campaign to expand Technical Education in Tanzania in the mid 980's. The college was constructed and equipped under the technical cooperation agreement between the Government of the United Republic of Tanzania and the government of the former Union of Soviet Socialist Republic (USSR). It was officially launched on 1st September, 1986 with students' enrollment in four academic departments, namely; the Department of Civil Engineering, the Department of Electrical Engineering, the Department of Mechanical Engineering and the Department of General Subjects. The three engineering departments were offering Full Technician Certificate programs and the program duration was four years. In 1990, the Department of Architecture was established. In 1991 the curriculum was reviewed reducing the duration of the training programme of three years to match with other technical colleges in the country. From 1986 to broadly has supported major change initiatives in the Southern of United Republic of Tanzania.

The approach in this paper is on unique conditions that led to the formation of the university transformation, to the learning mechanisms that have been specifically designed and/or have evolved to meet changing needs, on leadership support, on inside and outside participant roles, and on individual, collective, and in the field of university transformation and change in four dimensions:.

First, change in growth mode, there is a clear indicator after the transformation the university has evolved into the College of Engineering and Technology (CET), Institute of Science and Technology (IST), School of Business Studies (SBS) and three Centres. Their growth model was under the "The Strategic Fitness Process (SFP)" builds on the creation of an organizational dialogue facilitated via a task force of selected head of departments who are trusted by both senior management and the broader university. In 2011 this SFP they visited the NM-AIST, in the northern part of the united of republic of Tanzania. Their model advances the notion of "fit" (i.e., that strategy, structure, culture fits the present environment) and the need to develop "fitness" capability (i.e., the capacities to continually adapt and learn to the ongoing environmental changes in the hyper competitive markets). Fitness is to be achieved by creating a system for safe, open, and honest conversations between top management and the rest of the university about the direction of the university and what it takes to implement that direction. Meanwhile the core of SFP, one can find the commitment to successful organizational transformation on, the design and management of learning mechanisms, and the ongoing commitment to the creation and enhancement of learning.

The SFP approach suggests that stage models for organizations change, moving from a present state to a desired state is not enough, but rather advances the need to create systems that are 
capable of continuously transform themselves through iterative cycles of learning. The SFP is built around three fundamental dimensions of how to overcome the silent killers: create a quality of strategic direction for the university; improve the quality of learning, and enhance the quality of implementation. Beer claims that the method has been refined, tested, and implemented in hundreds of companies around the world since the 1990s (Beer, et al., 2009).

Second, Management was seen as visible and competent. The wide variety of university- wide planned change models and orientations can be found in the fields of change management and organization development and change; few are concerned with the development of new and ongoing organizational capability.

Third, despite the fact that many of the organization, development and change, growth models focus on organizational transformation, most do not address the institutionalization of learning mechanisms.

Fourth, a most important shift in the principles guiding organization development and change and the business models underlying strategies are required, since prior principles and models rely on phases, activities, and processes that facilitate change and not in the development of capabilities that will enhance the facilitation of continuous change with almost no time for crafting a change process and change phases.

We anchored the study in a university transformation effort. Capability development is at the heart of sustainable new product development process(Eisenhardt \& Martin, 2000; Winter, 2003).

\section{ORGANIZATIONAL LEARNING AND LEARNING MECHANISMS}

In this transformation, there are two actions involved, the "Participatory Action Research (PAR)" and the "Strategic Fitness Process (SFP)". In PAR, the emphasis was on active participation by all members of the MTC during the research process of the need of the transformational change and getting into MIST, researcher involvement in the action, this was done during the 1986 to 2005. At SFP, the emphasis was on the task force team, and giving the feedback to the management, the work period was between the 2005 and 2012 where the MIST changed to MUST. Research by the(Coghlan \& Shani, 2008) has shown that the most essence of learning mechanisms of the organization are in three categories; Cognitive, Structural, and procedure aspects are the engine that nurtures the community of inquiry. We will briefly give what is the meaning of these three categories, but not in exhaustive look, since it is beyond of our scope of this paper

Cognitive or cultural mechanisms are the bearers of language, concepts, symbols, theories, frameworks, and values for thinking, reasoning, and understanding developed in creating new organizational capabilities (Fredberg, Norrgren, \& Shani, 2011). Cognitive mechanisms are management's main means for creating an understanding among all employees of the rationale for change. Therefore, at this point we might look at the original rationale for creation of MUST parallel learning mechanism. The management created an environment both inside and outside of clear understanding the purpose and goals of the transformation, without compromising the quality of the education, and some could think that probably some employee they are looking to 
be recognized, this is one of the barriers on this aspect of cognition, but we are happy the management resolved this matter and created a good atmosphere for the understand inside/outside. From the outset, the cognitive aspects of the MUST learning mechanism have emphasized opening new lines of communication that would supplement hierarchical communications and creating forums for expression of opinions on all matters.

Structural learning mechanisms are organizational, physical, technical, and work system infrastructures that encourage practice-based learning. These mechanisms support dialogue and the sense-making entailed as individuals and groups learn from experience (Choo, 1996; Smith, 2001). For example, development forums can be established to share experiential learning laterally and vertically (Bjerlöv, Docherty, Boud, Cressey, \& Docherty, 2006). In this article MUST case, aspects of the structural learning mechanism include the new vertical and horizontal communication channels enabled by the parallel learning mechanism, changes in roles and teams for those participating in the research, formal and informal forums for joint employee/management exploration and debate, and networks for mutual learning(Bushe, 1991).

Procedural mechanisms can be multi-level or cross-community. Democratic dialogues (Gustavsen, 2001), work-based dialogue (Bjerlöv, et al., 2006), and similar methods allow the players to systematically learn from each other (Fredberg, et al., 2011). Later sections of this paper will cover interview, diagnostic and other methods and tools tailored to the MUST set. In the literature, the collective aspects of the learning mechanism, cognitive, structural, and procedural are called the "tapestry of learning mechanisms." Tapestry has interesting links to the original organization design concepts of design choices and "fit" among choices (Galbraith, 1977). Various accounts of tapestries or configurations created for complex settings have recently been published: For example, the Ericsson case (Fredberg, et al., 2011); and Dutch Multinational(Schuiling \& Aelbrechtlaan, 2014). Therefore, notion that some learning mechanisms, such as relational mechanisms, emerge and are not subject to design. Moreover, we will see in cases below that aspect of learning mechanisms evolve over time to reflect the changing environment, and potentially go against the original intent and official guidelines. The tapestry of learning mechanisms associated with the pharmacy operation parallel learning mechanism will be examined in depth to uncover these anomalies. We will align on case examples, interviews with outside researchers, and historical documents that reveal the evolution of forums in MUST in the United Republic of Tanzania.

\section{METHODOLOGY}

This paper builds on a seven -year longitudinal collaborative research study of the transformation process Mbeya University of Science and Technology (MUST), Tanzania. This paper provides a look at four various sources of data: participation observation, person and email interviews with three of the main actors within the MUST; archives related to the communications forum (MUST); and finally, prior publications featuring analysis of MUST agendas, processes, and outcomes.

Participant observation has been used in a variety of disciplines as a tool for collecting data about people, processes, and cultures in qualitative research. (Marshall \& Rossman, 2014) define observation as "the systematic description of events, behaviours, and artifacts in the social setting 
chosen for study. Observations enable the researcher to describe existing situations using the five senses, providing a "written photograph" of the situation under study (Erlandson, 1993). The report by (De Munck \& Sobo, 1998) describe participant observation as the primary method used by anthropologists doing fieldwork. Fieldwork involves "active looking, improving memory, informal interviewing, writing detailed field notes, and perhaps most importantly, patience" (DeWalt \& DeWalt, 2010). Participant observation is the process, enabling researchers to learn about the activities of the people under study in the natural setting through observing and participating in those activities. It provides the context for development of sampling guidelines and interview guides (DeWalt \& DeWalt, 2010). The author on (Schensul, Schensul, \& LeCompte, 1999) define participant observation as "the process of learning through exposure to or involvement in the day-to-day or routine activities of participants in the researcher setting" The following reasons for using participant observation in research:

- to identify and guide relationships with informants;

- to help the researcher get the feel for how things are organized and prioritized, how people interrelate, and what are the cultural parameters;

- to show the researcher what the cultural members deem to be important in manners, leadership, politics, social interaction, and taboos;

- to help the researcher become known to the cultural members, thereby easing facilitation of the research process; and

- to provide the researcher with a source of questions to be addressed by participants

\section{THE INTERNAL AND EXTERNAL RESEARCH ROLES IN CLINICAL INQUIRY}

In writing about the university transformation approach to university research. I introduce the notion of the clinical inquiry approach to this research, as a form of action research: What do I mean by clinical inquiry? For the purposes of this paper, I mean thus helping professionals who get involved with individuals, groups, communities, or organisations in a helping role. This would include those activities contributing to the University for the sustaining their transformation and endeavouring to lead in science and technology.

For example, discuss why nursing clinical inquiry is important and valued among the health care team? Here you will see the role of a nurse is to assist the individual, sick or well, in the performance of those activities contributing to health or the recovery of health. Therefore the same principle had been adopted to help individual or groups to identify the importance of the transformation and align with the vision and mission of the transformation of the university.

Clinical inquiry: is the process of intervention interferes with the client's in that it attempts to get the client their story out in their own way and to think about the reasons and causal linkages.

The various inquiry interventions produce insights on the part of both the forum members and the researchers. This closely follows the distinguishing features of internal and external research, in that members of the research team differ in physical and psychological connectedness to the organizational setting and the questions being examined in this epistle the clinical enquiries will base on the internal and external research. 


\section{PART ONE INTERVIEWS (STAFF)}

Daniel: What impact did the growth / transformation have on the environment structure?

Patrick: The transformation of the university has a great impact to the southern part of the United Republic of Tanzania, since most of the industry is around to that zone. Therefore the university has a great role to play in the research and innovation projects which should address new model solution to the companies' products.

Daniel: It started as a technical education and has evolved to create a different configuration. What are the issues connected with this?

Devota: It is clear that it was operated as a technical education and it's evolving to create a different configuration which is a more complex situation, university transformation must be based on a different paradigm. The transformation is required when the environment itself changes qualitatively, drastically, and almost always discontinuously, engineering a radical break with the past. The old way of doing things no longer works, even though you are doing it the best way you can.

Daniel: Is technical education still in operation?

Devota: It is still operating under the Institute of Science and Technology (IST) is an educational strategy for providing with the academic, technical, and employability skills and knowledge to pursue for further studies. Today's economy demands a better educated workforce than ever before, and jobs in this new economy require more complex knowledge and skills than the jobs of the past.

Daniel: Other changes led to different representation within the University?

Devota: The university moved by the idea of science and technology for the innovation action research, and expanding their branches, to the other regions for the covering of this challenge.

Daniel: How is the collaboration involved in this?

Patrick: There was clear, shared and understanding the goal and the purpose of this collaboration was to involve the inside / outside researchers to participate fully in the transformation process. It creates an opportunity for industry and the Small and Medium Enterprises (SME) to exchange ideas and information between meetings.

\section{Daniel: What is the MUST role?}

Sunday: Msambichaka felt you can't overdo science and technology. It has a unique role, the role of MUST aims at providing the technical knowledge, scientific and technological research, and developing skills. Meanwhile very few companies support basic research since it is very far from the company market, to bridge this gap MUST plays a very big role in the applied research. 
Daniel: It sounds like you (Devota) feels the university has matured and learned to get people involved, get feedback, and work together across all the locations and stakeholders. What roles have Msambichaka and other actors played?

Devota: Msambichaka helped at startup the transformation and establishing the framework and the processes. As a University effectiveness person, he asked the difficult questions and challenged us to allot with the issues and to establish ways to dish out with what was an ugly time in our history. He has been the constant person to facilitate meetings. He helps us to organize the agenda and bring up the issues that we would rather push aside. Departmental representation changes a lot at the meetings. Furthermore, it is significant to have a disinterested party, because otherwise you can run the risk of operating the staff meetings, thus he invited outside employees. He also brings learning activities, exercise, and tools that help us to be more effective. We can carry these back to our own college, school and department. I practiced many of them with my own management team.

Daniel: You and Msambichaka have written together. What kind of audiences are you interested in reaching and what kind of knowledge are you creating?

Mhiru: The audience is informed the society, industry and the Small and Medium Enterprises (SME). If we write about the university, it's something any institution can do. The articles have been about learning mechanisms. I 'am an academic, but also in the civil engineering practice in the world. Writing involves the same kind of bridging between theory and practice that we do at the university.

Daniel: What is your role in the research and what comes out of the collaboration?

Mhiru: When I was starting out in research, I was afraid to collaborate. By not recognizing the significance of collaboration. I didn't think I could give something in return. When I started the co-authoring with Msambichaka on general management issues. When I work with Msambichaka I see why the ideas and collaboration are effective. Composing is a totally different locale for me from my normal life; to be able to touch on management theory and understand things in a manner that it can be gone past on so others can utilise it. That was naive. Collaboration is about much more than simply sharing data or sharing techniques.

Daniel: The university has involved the collaboration with the USSR. What is good collaboration?

Susan: The concept of broader impacts should extend beyond benefits to graduate or undergraduate students. Partnering between the university and USSR is beneficial to the university as it allows both partners to build off of each other's' expertise and infrastructure to be constructed for the university. When people come to a university, they expect to see state of the art science and technology.

Daniel: Could you provide some examples of where the university learned and did something different? 
Kayuki: The university learned from NACTE and did something different during the transformation from MTC to MIST. The teaching/learning changed from knowledge based to competence based system. This was something very different from the previous system. The mode of assessment also took a different system

Daniel: What is Msambichaka's role?

Sunday: Msambichaka is well considered as a credible person. The community feel that he has contributed to the university structure and the incredible transformation. Msambichaka taught us and developed us without making us feel that we didn't know how things work - allowing us exposure to a level without making us feel that we were on opposite sides. He taught us the importance of voicing our opinions and how to give back. He gave us the tools. I got to go back and facilitate at a local level, which I never would have thought I could have done. Even those who replaced us could learn to do it, and it became a natural way for things to happen. I never felt intimidated to voice my opinion because I felt I was speaking for the group.

Daniel: Has the university had learnings from management?

Judith: The management keeps alive the thought that principals, deans and head of departments have to think about what they say and how they say it. Management tends to simply blast out information. But now they know that if they don't taste it in the field first, they are going to have to reckon with it. When the top management group has a special issue to resolve, they will form a special group to address it and bring it back to management. People are ready to contribute feedback to management. Nowadays we suffer an annual people pulse survey where employees are surveyed about the university environment, and management sets goals based on the data. This is a report card on how employees feel about the university and management.

Daniel: How is the collaboration between the university and the industries?

Lilian: The collaboration between the university and the industry has always been an important but complex topic. Due to the rapid evolution of the business environment and the vast transformations throughout the academic realm, the subject is now even "hotter" than it has been. Despite of that fact, the university can be major resources in an industry's innovation strategy. The university creates an opportunity for a company or industry, such as guidance for the direction of technology development. Here's what matters it not the outcome, but the impact how the new knowledge derived from collaboration with a university can contribute to a company's or industry performance.

\section{PART TWO INTERVIEWS (STUDENTS)}

Daniel: What do you think are the needs of the tertiary public education university in Mbeya?

Mica: I think the basic needs of the tertiary public education university in Mbeya are as follows: Increase of learning or schooling facilities, increase the capacity of the collaboration with the industries, involvement of non-government organization, increasing number of facilitators or educators and improvement of learning or teaching Programs. 
Daniel: Which of the needs of public education you listed above are being satisfied?

Mica: Among of the needs of public education are being satisfied: Involvement of nongovernment organization (NGO'). It has been observed that there an increase of NGO'S involved in supporting and even investing in tertiary public education university, either by providing education sponsorship to some people in the region, or establishing tertiary public education universities to enable a large number of people to join various faculties.

Daniel: Which needs you listed are not being satisfied? What is the primary restriction of each need?

Mica: Among the needs which are not being satisfied are: Increase of learning or schooling facilities, the mentioned needs are not being satisfied due to some restriction such as Lack of capital to purchase, schooling facilities, lack of full government involvement.

Daniel: Do you think the transformation of the University has a positive impact?

Mica: YES: transformation of the university has a positive impact on the government, society as well in the entire world. It has lead to an increase of various learning faculties, and hence many people opt to join various programs or courses in the university.

Daniel: List the benefits you receive from the Government as a student at this university?

Mica: These are the benefits which I receive from the government as a student: Education sponsor and acquiring technical knowledge.

Daniel: What issues or obstacles did you and your parents face to ensure your enrolment in your university?

Isomanga: Issues including financial situation, especially in the area where the direct cost involves the parents, most families have low income and they also not eligible to get loans from financial institutions Procedures of enrolment including TCU/NACTE require application fees as well as the access of internet which require some financial power.

Daniel: What issues or obstacles do you face as an enrolled student?

Isomanga: The problem faced as an enrolled student is availability of learning materials, especially if it involves stationery cost, for loan board beneficiary student the amount set aside is not enough.

Daniel: What does the company /industry do to benefit the faculty of the university which you are enrolled in?

Jackson: The company/ industry always does the following benefit the university: Industry / Company has always benefited the faculty through various sponsorship eg. Providing some learning materials such as practical equipments, chemical, books, etc., likewise companies assist 
students to attend the practical training program to transform their theoretical learning's into real practice.

Daniel: What issues or obstacles do you think your faculty are facing?

Jackson: One of the major obstacles the faculty is facing is communication between the industrial and my faculty, there is a silent siren.

Daniel: What issues do you think the management has not considered during the transformation of the university?

Jackson: There is a pressing need for university to answer swiftly and effectively to the radical changes of the science and technology that are being wrought by an unforgiving and, at times, even hostile environment. The pressures and challenges of change have led to some of the staff were lagging behind with the transformation, to match with the transformation likewise to the student copying with the schedule which is more complicated, the management forgets to put across intelligibly.

Daniel: What else could the government and the industry do to benefit the faculty of your university?

Jackson: Both government and industry must invest more capital on learning facilities and technology to benefit the faculty of the university

\section{PART THREE INTERVIEWS (INDUSTRIES / COMPANY)}

Daniel: How can companies best achieve competitive impact from industry - university research collaborations?

Haivenje (Atlas Copco Tanzania Limited): Atlascopco Tanzania Limited is customer centre of Atlascopco Group, which is manufacturer, supplier and Service Company of Mining, construction equipment and industrial tools. As a customer centre, Atlascopco Tanzania Limited advances to be first in mind - first in choice for the entire customer. Qualities of products distinguish to other product in the market. Well-organized after-market service hold up the product brand integrity. University researches assisted company technology and business management, according to technology advances. Using university research distinguishes the company operates against competitors in handling customers.

John $(T B L)$ : Through Industry - University research collaborations my company achieves a lot because there are many issues which can be resolved through research which are performed by industry- university research team from MUST.

Daniel: How the university research team how the collaboration is helping your company?

Haivenje (Atlas Copco Tanzania Limited): University research does help the company to improve sales and services to the customers. In spite of the fact of having competitors in 
business, or use of researches in business and market overview brings the company name as the first in mind and the first choice

John $(T B L)$ : The collaboration with the Industry - University research team is helping us much because when we have problems to be resolved they give us required support on time.

Daniel: Do you think the university has built more industry links to improve graduate employability?

Haivenje (Atlas Copco Tanzania Limited): Indeed, the University has developed the capability of graduate to be employable.

John $(T B L)$ : Yes the university has built more industry link to improve graduate employability, for instance, two to three times per week, students from Mbeya University are coming to our company for practical learning and collecting issues which require support from the University.

Daniel: What is the level of employment of the students in your organization?

Haivenje (Atlas Copco Tanzania Limited): Atlascopco Tanzania limited staffs education levels are MSC in Engineering, BSC in Engineering, BEng in engineering, Full Technician Certificate in Engineering, Diploma in Engineering and Basic Certificate in Engineering. There are supportive departments like human resource management, accounts and finance, and marketing.

John TBL: The levels of employment of students in my organization are very high, almost ninety percent of the students who are working in the engineering department are graduating from the Mbeya University Of Science and Technology (MUST)

\section{DISCUSSION}

Several methods had adopted in the seven -year longitudinal collaborative research study of the transformation process Mbeya University of Science and Technology (MUST), One was the Strategic Fitness Profiling (SFP). The key components of Strategic Fitness Profiling (SFP) approach to research, change and development are designing and implementing the platform for learning, inventing new learning mechanisms, the agile nature of learning mechanisms and leading transformation through learning mechanisms. In order to align with the key components there is a clear schedule of the training staff, to the reputable university.

Intervention research (IR) does not impose any methods, but requires involving any relevant actor who is knowledgeable about or involved in creativity and its formalization into models, tools and procedures, whereby all actors are granted equal access to research, and being consistent with the epistemology of IR. The study progressed accordingly. First, we identified a research team (SFP) involving in the university transformation. The combined expertise of these actors covered the entire creative process and represented the specific interests that needed to be accommodated. The need for a continuous involvement in the research process limited number of employees that could be allocated in the team. 
In general terms, the research combined different qualitative (mail interviews, Facebook interviews, observations) and quantitative (an exploratory survey) techniques which were all instrumental to a common purpose, i.e. to understand the social interactions, contextual conditions and individual involvement that characterize creativity processes. These data were processed by the research team during the roundtable meetings in order to develop models of collective actions.

\section{CONCLUSION}

The need arises in various domains for seven-year transformation effort of MUST and provided the empirical case for this paper. The paper captured the complex transformation process, mechanisms, activities, and outcomes. The coherence of the SFP orientation coupled with the design and implementation of learning mechanisms provided the engine for the transformation effort. The article contributes by providing rich data on university practice related to the transformation of the university capabilities. Moreover, developing agility by engaging people at all levels in continuous learning about what needs to change and decentralize how this should be solved might be the path to follow.

\section{REFERENCES}

[1] Beer, Michael, Eisenstat, Russell A, \& Foote, Nathaniel. (2009). High commitment high performance: How to build a resilient organization for sustained advantage: John Wiley \& Sons.

[2] Bjerlöv, Monica, Docherty, Peter, Boud, D, Cressey, P, \& Docherty, P. (2006). Collective reflection under ambiguity. Productive Reflection at Work: Learning for Changing Work, 93-105.

[3] Bushe, Gervase R. (1991). Parallel learning structures: Increasing innovation in bureaucracies: Addison-Wesley.

[4] Chapman, C Richard, Lipschitz, David L, Angst, Martin S, Chou, Roger, Denisco, Richard C, Donaldson, Gary W, . . Gilson, Aaron M. (2010). Opioid pharmacotherapy for chronic non-cancer pain in the United States: a research guideline for developing an evidence-base. The Journal of Pain, 11(9), 807-829.

[5] Choo, Chun Wei. (1996). The knowing organization: How organizations use information to construct meaning, create knowledge and make decisions. International journal of information management, 16(5), 329-340.

[6] Coghlan, David, \& Shani, AB. (2008). Insider action research: The dynamics of developing new capabilities. Handbook of action research, 643-655.

[7] De Munck, Victor C, \& Sobo, Elisa J. (1998). Using methods in the field: a practical introduction and casebook: Rowman Altamira.

[8] DeWalt, Kathleen M, \& DeWalt, Billie R. (2010). Participant observation: A guide for fieldworkers: Rowman Altamira.

[9] Docherty, Peter, Shani, AB, Mohrman, SA, Pasmore, WA, Stymne, BA, \& Adler, N. (2008). Learning mechanisms as means and ends in collaborative management research. Handbook of collaborative management research, 163-182.

[10] Eisenhardt, Kathleen M, \& Martin, Jeffrey A. (2000). Dynamic capabilities: what are they? Strategic management journal, 21(10-11), 1105-1121. 
[11] Erlandson, David A. (1993). Doing naturalistic inquiry: A guide to methods: Sage.

[12] Fredberg, Tobias, Norrgren, Flemming, \& Shani, AB. (2011). Developing and sustaining change capability via learning mechanisms: A longitudinal perspective on transformation. Research in organizational change and development, 19, 117ł̀161.

[13] Galbraith, Jay R. (1977). Organization design: An information processing view. Organizational Effectiveness Center and School, 21.

[14] Garvin, David A, Edmondson, Amy C, \& Gino, Francesca. (2008). Is yours a learning organization? Harvard business review, 86(3), 109.

[15] Gustavsen, Bjфrn. (2001). Theory and practice: The mediating discourse. Handbook of action research: The concise paperback edition, 17-26.

[16] Marshall, Catherine, \& Rossman, Gretchen B. (2014). Designing qualitative research: Sage publications.

[17] Phills, James A, Deiglmeier, Kriss, \& Miller, Dale T. (2008). Rediscovering social innovation. Stanford Social Innovation Review, 6(4), 34-43.

[18] Schensul, Stephen L, Schensul, Jean J, \& LeCompte, Margaret Diane. (1999). Essential ethnographic methods: Observations, interviews, and questionnaires (Vol. 2): Rowman Altamira.

[19] Schuiling, Gertjan, \& Aelbrechtlaan, Graaf. (2014). Changing Leadership Dynamics at Agility-Critical Interfaces: Action Research as a 25-Year Longitudinal Study. Abraham B.(Rami) Shani, Debra A. Noumair (ed.) Research in Organizational Change and Development (Research in Organizational Change and Development, Volume 22) Emerald Group Publishing Limited, 22, 219-297.

[20] Smith, Peter. (2001). Work-based Learning: The New Frontier of Management Development. Journal of Workplace Learning, 13(6), 260-261.

[21] Verganti, Roberto. (1999). Planned flexibility: linking anticipation and reaction in product development projects. Journal of Product Innovation Management, 16(4), 363376.

[22] Verganti, Roberto. (2013). Design driven innovation: changing the rules of competition by radically innovating what things mean: Harvard Business Press.

[23] Winter, Sidney G. (2003). Understanding dynamic capabilities. Strategic management journal, 24(10), 991-995.

[24] Worley, Christopher G, \& Lawler, Edward E. (2010). Agility and Organization Design:: A Diagnostic Framework. Organizational Dynamics, 39(2), 194-204. 